Dept. of Pathology,

Animal Health Research Institute, El-Mansoura Lab.

\title{
PATHOLOGICAL STUDIES ON SOME MYCOTIC DISEASES IN BALADY CHICKEN
}

(With 3 Tables and 17 Figures)

By

\author{
SH. ABDEEN; DOAA A.H. EL-MATARY \\ and $\mathrm{H} . \mathrm{M} . \mathrm{MOUSA}$ *
}

*Animal Health Research Institute, Zagazig Provincial Vet. Lab.

(Received at 7/4/2009)

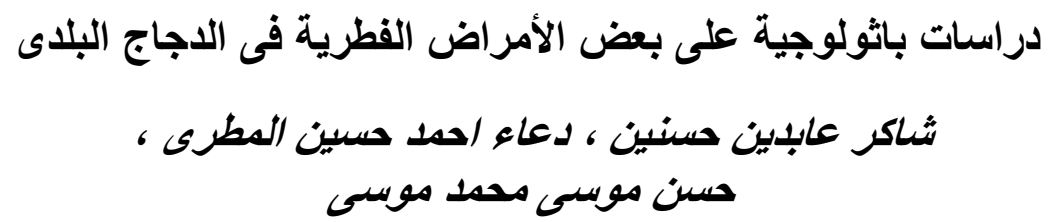

أجرى هذا البحث على أربعة مزارع للاجاج البلدى بمحافظة الدقهلية خلال الفترة من نوفمبر

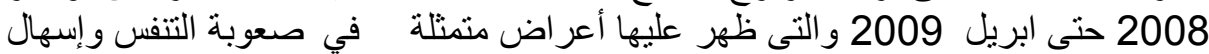
ونقص فى وزن الجسم وبعضها بها انتفاخ فى الحويصلة مع ترجيع للأكل بر ائحة كريهة.

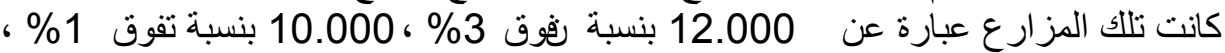

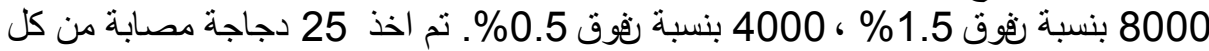

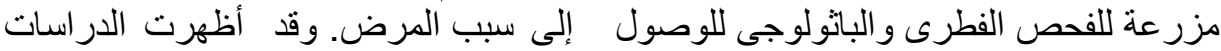

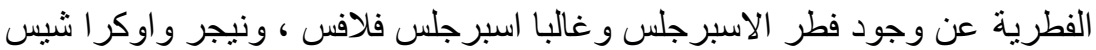

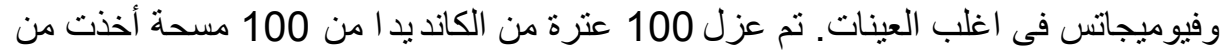

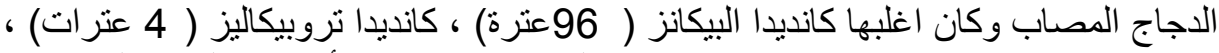

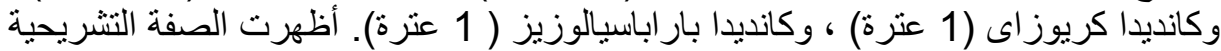

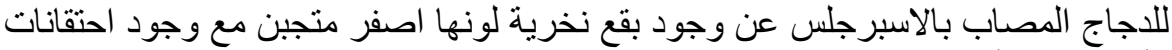

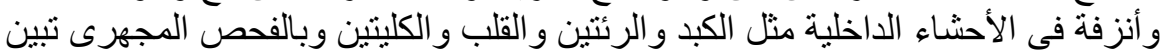

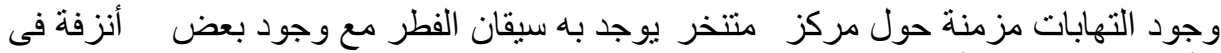

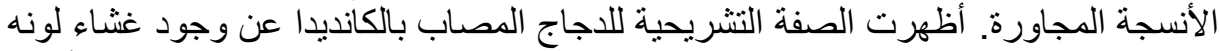

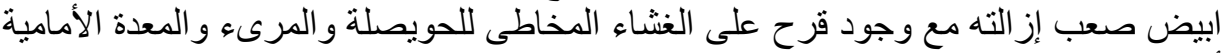

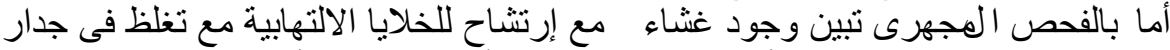

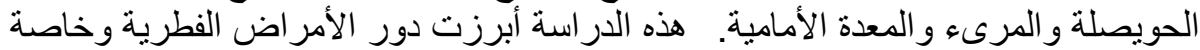

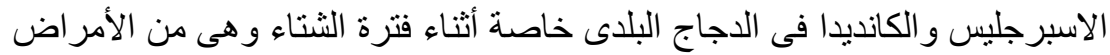

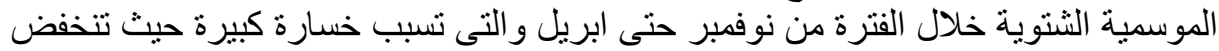

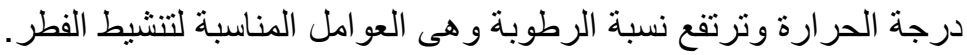

\section{SUMMARY}


This study was performed on 4 Balady chicken farms in Dakahlia Province during the period from November, 2008 to April 2009. These farms suffered from difficult respiration, diarrhea and decrease body weight. Other birds suffered from swollen crop and regurgitate of slimy foul smelling food. These farms in $(12.000,10.000,8.000$ and 4.000) with $(3 \%, 1 \%, 1.5 \%$ and $0.5 \%)$ mortality rate respectively. Their ages ranged from 25 to 120 days. Twenty five birds were taken from each farm for mycological and pathological examination. Macroscopically small garish white or yellowish fragil nodules of $1 \mathrm{~mm}$ diameter were noticed in lung, air sacs, heart, liver, intestine, proventriculus and skeletal muscles. Mycological examination revealed the isolation of Aspergillus species which identified by biochemical reaction as Aspergillus (flavus - niger, ochraceous and fumigatus). Histopathologically, numerous caseated nodules were observed in the pulmonary tissues, the nodular with a caseous necrotic center surrounding with lymphocytes, macrophage and giant cells. Congestion and haemorrhage were noticed in the liver, heart, kidney along with septated hyphae of Aspergillus. Other birds revealed the isolation of Candida species were isolated from other birds which were identified as C. albicans (94) C. tropicalis (4), C. krusei (1) and C. parapsillosis (1). These birds revealed thickening of the mucosa of the oesophages, crop, proventriculus and gizzard which initially covered by slimy material these lesions progressed to diphtheritic membrane which was difficult to be removed. Histopathologically, hyperplastic changes were reported in the cornified layers of the crop, oesophagus and proventriculus with degeneration and necrosis of the superficial mucosa. The necrotic mucosa were covered with diptheretic membrane with intensive leukocytic infiltration in submucosa. This study investigate the role of mycotic disease specially Aspergillus and Candida species in balady chicken farms during winter season. Increase of humidity with lowering of temperature during the period from November to April is the main predisposing factor for mycotic disease in balady chicken farm. In these studies the role of aspergillosis and candiasis in balady chickens farms was investigated. It was reported that increased humidity and low temperature (November to April) predispose for mycotic infection.

Key words: Chicken, mycotic diseases, pathology

\section{INTRODUCTION}


Mycotic diseases in poultry causing high economic losses. Particularly when associated with other stress conditions (Ononiwu and Momoh, 1983). Aflatoxin increased the infectivity of Aspergillus fumigatus and Candida albicans as measured by lesion score (El- Mahdy et al., 1994).

Hossain et al. (2004) recorded that the incidence rate of aspergillosis in poultry during the period of January 2001 to February 2002 was $2-4 \%$.

Many authors isolated Aspergillus spp. and Candida spp. as an etiological agent of mycotic infection in poultry. Edris et al. (1995) and isolated Aspergillus spp., also Said and Sampurant (1994) isolated the Candida spp. El-Saida (1998) isolated Aspergillus and Candida species from broiler farms.

Fungal infection is considered as stress factor affecting the hatchability, growth and development of birds (Cutsen and Fram 1987 and El-Badry and Jokkar, 1988).

Environmental factors such as warmth and humidity play a role in mycotic infection (Beckman et al., 1999).

Many researchers proved the clinical signs in poultry (Bergmann et al., 1980; Chaudhry et al., 1992; Samad and Chakraborty, 1993; Akan et al., 2002 and Rahman et al., 2003) who mentioned that locomotors disorders and losses involving $0.5-1.5 \%$ of the chicks between $7-28$ days of ages had occurred in two broiler farms for about six months. Paralysis, ataxia and torticolls due to aspergillus infection were recorded in chickens of 4 months ages by (Kwonyogkuk et al., 1998).

Moreover, candidiasis caused lesion in digestive and respiratory tracts. El-Batrawi, (1980) isolated 60 Candida albicans from crops of 159 chicken suffering from drop in egg production and diarrhea. The affected birds had tendency to regurgitate food with slimy and foul smelling discharge (Choudhry et al., 1992; Carrasco et al., 1993 and ElSaida, 1998).

Clinical signs including locomotors and mortality rate of about 0.5 - $1.5 \%$ were recorded by Bergmann et al. (1980) among chicken of 7 28 days aged due to Aspergillus fumigatus infection.

The main gross lesions reported in Aspergillus infection in chickens were the presence of white to yellow caseous nodules in lungs, thoracic air sac, cerebellum, liver, heart, spleen kidney, pancreas and intestine (Chudhry et al., 1992; El-Saida, 1998 and Akan et al., 2002).

This study was designed to investigate the role of Aspergillus and Candida species in indication of disease among balady chicken with 
special consideration to clinical signs, pathmorphological lesion in addition to isolation and identification of the causative agents.

\section{MATERIALS and METHODS}

\section{(A) Samples:}

This study was applied on balady chicken during the period from November 2008 to April 2009 (their ages varied from 25 to 120 days old). Inappetence, accelerated breath, decrease body weight, diarrhea and some birds had tendency to regurgitate slimy and foul smiling discharge were the main symptom observed.

The morbidity and mortality rate were obtained from 4 farms $(12.000,10.000,8.000$ and 4.000) in Dakahlia province. 25 diseased bird were obtained from each farm for pathological examination and detection of the causative agent.

Table 1: Summarized examined flocks, their numbers age, mortality and morbidity rates and number of samples

\begin{tabular}{|c|c|c|c|c|c|}
\hline $\begin{array}{c}\text { No. of } \\
\text { flock }\end{array}$ & $\begin{array}{c}\text { No. of } \\
\text { samples }\end{array}$ & $\begin{array}{c}\text { No. of } \\
\text { bird /flock }\end{array}$ & Age/day & $\begin{array}{c}\text { Morbidity during } \\
\text { the course of } \\
\text { disease }\end{array}$ & $\begin{array}{c}\text { Mortality during } \\
\text { the course of } \\
\text { disease }\end{array}$ \\
\hline 1 & 25 & 12.000 & 35 & $20 \%$ & $3 \%$ \\
2 & 25 & 10.000 & 120 & $16 \%$ & $1 \%$ \\
3 & 25 & 8.000 & 25 & $10 \%$ & $1.5 \%$ \\
4 & 25 & 4.000 & 25 & $8 \%$ & $0.5 \%$ \\
\hline
\end{tabular}

Samples from lungs, liver, heart, kidneys, proventriculus, crop, muscles, intestine, spleen and brain were collected for isolation and identification of Aspergillus species and Candida species.

\section{(1) Isolation of fungi:}

The chicken surface were sterilized by moistening of piece of cotton with ethyl alcohol $70 \%$ then swab from liver, kidney, lungs, heart, brain, crop, proventriculus, pectoral muscle and thigh muscle were obtained and inoculated into duplicates plates of Sabouraud's dextrose agar with $0.05 \mathrm{mg} / \mathrm{ml}$ chloramphenicol inoculated plates were inoculated at $25^{\circ} \mathrm{C}$ and $37^{\circ} \mathrm{C}$ for $5-10$ days.

\section{(2) Identification of the isolated moulds:}

(a) Macroscopic examination: 
By studying the morphological characters of colonies including gross appearance of culture rate of growth, texture and color of colonies (above and reverse side) according to Ellis (1971); Laron (1976) and Refai (1969).

(b) Microscopic examination according to Dovorak and Actenasek, (1969):

The reported slides examined under low and high power to characterized stages, head, vesicle, strigmata and conidiophore.

(B) Identification of yeast according to Barnett et al. (1983):

Identification was done for subcultured isolates on Sabouraud's dextrose agar according to the following:

(1) Gross appearance: concerning its size and consistence.

(2) Microscopic examination: by wet preparation using high power magnification for presence of yeast cells and on rice agar media for detection of chlamydospores, blastospores and pseudohyphae.

(3) Biochemical reaction: were done as sugar fermentation, sugar assimilation, nitrate assimilation and urea hydrolysis for complete identification of yeast.

\section{Pathological examination:}

Postmortem examination had been done to the diseased chicken. Specimens from lung, liver, kidneys, brain, proventriculus, heart, muscles, spleen, intestine and crop were collected and fixed in 10\% neutral buffered formalin. Paraffin section of $5 u$ thickness were prepared and stained with $H \& E$ and periodic acids Schiff reaction (PAS) for microscopic examination (Bancroft et al., 1990).

\section{RESULTS}


Table 2: Incidence of Candida species in chicken with crop mycosis.

\begin{tabular}{|c|c|c|c|c|c|c|c|c|c|c|c|c|c|c|c|c|c|c|}
\hline \multirow{2}{*}{$\begin{array}{l}\text { Genera } \\
\text { of fungi }\end{array}$} & \multicolumn{2}{|c|}{ Liver } & \multicolumn{2}{|c|}{ Kidney } & \multicolumn{2}{|c|}{ Lung } & \multicolumn{2}{|c|}{ Heart } & \multicolumn{2}{|c|}{$\begin{array}{l}\text { Pectoral } \\
\text { muscle }\end{array}$} & \multicolumn{2}{|c|}{$\begin{array}{l}\text { Thigh } \\
\text { muscle }\end{array}$} & \multicolumn{2}{|c|}{ Crop } & \multicolumn{2}{|c|}{ Proventriculus } & \multicolumn{2}{|c|}{ Brain } \\
\hline & No & $\%$ & No & $\%$ & No & $\%$ & No & $\%$ & No & $\%$ & No & $\%$ & No & $\%$ & No & $\%$ & No & $\%$ \\
\hline $\begin{array}{l}\text { Aspergillus } \\
\text { spp. }\end{array}$ & 100 & & 80 & & 28 & & 50 & & 80 & & 50 & & 30 & & 10 & & 60 & \\
\hline $\begin{array}{l}\text { Penicillium } \\
\text { spp. }\end{array}$ & 7 & & 13 & & 5 & & 10 & & 30 & & 10 & & - & & - & & - & \\
\hline $\begin{array}{l}\text { Mucor } \\
\text { spp. }\end{array}$ & 7 & & 35 & & 20 & & 40 & & 35 & & 30 & & - & & - & & - & \\
\hline $\begin{array}{l}\text { Candida } \\
\text { spp. }\end{array}$ & 25 & & 5 & & 25 & & - & & 20 & & 20 & & 100 & & 50 & & - & \\
\hline Rhodotorula & 10 & & 10 & & - & & - & & - & & - & & 3 & & 1 & & - & \\
\hline Trichosporon & - & & & & & & - & & & & - & & 5 & & 2 & & - & \\
\hline Total & 149 & & 143 & & 78 & & 100 & & 165 & & 110 & & 138 & & 63 & & & \\
\hline
\end{tabular}

Table 3: Member of Aspergillus species in examined chicken.

\begin{tabular}{|c|c|c|c|c|c|c|c|c|c|c|c|c|c|c|c|c|}
\hline \multirow{2}{*}{$\begin{array}{l}\text { Species of } \\
\text { Aspergillus }\end{array}$} & \multicolumn{2}{|c|}{ Liver } & \multicolumn{2}{|c|}{ Kidney } & \multicolumn{2}{|c|}{ Lung } & \multicolumn{2}{|c|}{ Heart } & \multicolumn{2}{|c|}{$\begin{array}{l}\text { Pectoral } \\
\text { muscle }\end{array}$} & \multicolumn{2}{|c|}{$\begin{array}{l}\text { Thigh } \\
\text { muscle }\end{array}$} & \multicolumn{2}{|c|}{ Crop } & \multicolumn{2}{|c|}{ Brain } \\
\hline & No & $\%$ & No & $\%$ & No & $\%$ & No & $\%$ & No & $\%$ & No & $\%$ & No & $\%$ & No & $\%$ \\
\hline A. flavus & 40 & & 50 & & 8 & & 20 & & 60 & & 30 & & 20 & & 40 & \\
\hline A. niger & 10 & & 20 & & 10 & & 10 & & 10 & & 10 & & 10 & & 15 & \\
\hline A. ochraceus & 30 & & 5 & & 10 & & 10 & & 6 & & 10 & & - & & 5 & \\
\hline A. fumigatus & 5 & & 5 & & - & & 5 & & 4 & & - & & - & & - & \\
\hline A. terrus & 5 & & - & & - & & 5 & & - & & - & & - & & - & \\
\hline A. candidus & 10 & & - & & & & - & & & & - & & - & & - & \\
\hline Total & 100 & & 80 & & 28 & & 50 & & 80 & & 50 & & 30 & & 60 & \\
\hline
\end{tabular}


Fig. 1: Lung of chickens (aspergillosis) showing caseated nodules replacing the pulmonary tissues in addition to congestion of pulmonary blood vessels and bronchitis (H\&E x 300)

Fig. 2: High power for Fig. (1) to show granulomatus inflammation surrounding caseated center with giant cell, arrows (H\&E x 1200)

Fig. 3: Lung of chickens (aspergillosis) showing septated mycelia(8) of Aspergillus fumogatus within the necrotic center with granulometus reaction (9) (H\&E x 1200).

Fig. 4: Lung of chickens (aspergillosis) showing caseated center (4) with septated mycelia (5) (PAS x 1200). 
Fig. 5: Liver of chickens (aspergillosis) showing caseated center with septated mycelia fungus (PAS x 1200).

Fig. 6: Liver of chickens (aspergillosis) showing portal fibrosis with massive inflammatory cells in addition to degenerated changes of hepatic cells (H\&E x 1200).

Fig. 7: Liver of chickens (aspergillosis) showing focal area of leukocytic reaction (H\&E x 300).

Fig. 8: High power of Fig. (7) showing aggregation of lymphocytes, macrophages and heterophils (H\&E x 1200). 
Fig. 9: Liver of chickens (aspergillosis) showing fibroblast, heterophils and giant cells around the granuloma replacing liver parenchyma (H\&E x 1200).

Fig. 10: Heart of diseased chickens (aspergillosis) showing caseated center in heart muscles (H\&E x 300).

Fig. 11: Kidney of chickens (aspergillosis) showing diffuse necrosis with neumerous round cell replacing renal parenchyma with small granuloma (H\&E x 300).

Fig. 12: Brain of chickens (aspergillosis) showing degenerated neurons, congestion and meningitis (H\&E x 300). 
Fig. 13: Intestine of chickens (aspergillosis) showing granuloma in the mucosa and submucosa with leukocytic infiltration (H\&E $\mathrm{x}$ 300).

Fig. 14: Proventriculus of chickens (spergillosis) showing aggregation of leukocytes between their glands (H\&E x 1200).

Fig. 15: Spleen of chickens (aspergillosis) showing necrosis and depletion of the white pulp (H\&E x 300).

Fig. 16: Crop of chickens (candidiasis) showing diphtheertic membrane (H\&E x 300). 
Fig. 17: Crop of chickens (candidiasis) showing subepithelial tissues intense with leukocytic infiltration (H\&E x 1200).

\section{DISCUSSION}

From 100 diseased chickens the most predominent fungal isolates were Aspergillus species followed by Candida spp. Mucor, Penicillium, Rhodotorula and Trichosporon species (Table 2). The liver, kidney were the most target organ of fungal infection followed by pectoral muscle and thigh muscle then heart and lung (Table 2).

Aspergillus (flavus, niger, ochraceus and fumigatus) were the most isolated species of Aspergillus while other species are rare (Table 3). These results agreed with those of Ajay et al. (1991); Barton et al. (1992); Bechman et al. (1994); Utomo et al. (1995) and Magnolli et al. (1998). Liver, kidney and lungs represent more organs exposed for infection by ingestion or inhalation of fungal spores while the heart was of low frequency in comparison with other organs. These finding was due to the fact that fungi spore must reach to the systemic circulation in order to reach to the heart. This required more time and the heart not exposed frequently for contamination of feed and drinking water as liver, kidney, and lung (Ismael, 1993; Singh et al., 1993 and Rageb et al., 1999). 
According to the present work 100 swabs were obtained from crops of chicken with crop mycosis, 100 Candida strains were isolated and identified as C. albicans (94), C. tropicalis (4), C. krusei (1) and C. parapsilosis (1). These results agreed to certain degree with that obtained by Taguchi et al. (1979); Osman, (1991) and El-Matary (1998) who found that Candida albicans was the most predominant Canidida species isolated from crop mycosis but disagreed with Taguchi et al. (1979) in the incidence of the other Candida species they isolated Candida galabrata in a higher incidence there is no distinct reasons for the variation in yeast species isolated but it may be due to the difference in yeast flora localities in which the researcher were done or may be due to the difference on the feeding status as mentioned by Manfre (1958).

Trichosporon represented 5\% of infection followed by Rhodotorula 3\%. Rhodotorula rubra represented all Rhodotorula isolated in this work. This yeast is the most common species of Rhodotorula isolated from gastrointestinal tract (El-Badry and Sokker 1988 and Osman, 1991).

\section{Pathological findings:}

\section{Aspergillus species:}

The main clinical signs in the present work were respiratory manifestations characterized by gasping, dyspnea and accelerated breath. These signs were also reported by Calnek et al. (1991); Edris et al. (1995) and El-Saida (1998). Signs indicated that aspergillosis is considered an air born infection and severity of outbreaks was related to the spore concentration in the air and lowered host resistance at the time of infection. The gross lesion of aspergillosis in our study were detected in lungs, air sacs, heart, liver, intestine, proventriculus, skeletal muscles, brain and spleen. The widely disseminated infection to these organs may be due to hematogenous or lymphatic dissemination of the organisms from the respiratory tract to these organs. These observations agreed with Beckman et al. (1994). The gross lesion were small garish white or yellowish fragile nodules of $1 \mathrm{~mm}$ to $2 \mathrm{~mm}$ diameter distributed allover the infected organs and tissues these results were completely inagreement with those mentioned by Gab-Allah (1994); Richard et al., (1994) and Ali (1996). Iskander et al. (1992) and Singh and Malhotra (1979) described a white nodular lesions of variable thickness in lungs thoracic air sac, heart, liver, spleen, pancreas, kidney, proventriculus and skeletal muscles.

The microscopic picture in this study was characterized by caseated nodules replacing the pulmonary tissues in addition to 
congestion of pulmonary blood vessels and bronchitis (Fig. 1). Granulmatous inflammation surrounding caseated center were seen with lymphocytes, macrophages and gaint cells (Fig. 2). Moreover, basophilic septated hyphae of Aspergillus fumigatus were noticed within the necrotic center with granulomatus reaction (Fig. 3). The aforementioned hyphae proved to be PAS positive (Fig. 4). Air sac appeared highly oedmatous and contained seriofibrinous exudates and septated basophilic hyphae liver showed massive tissue necrosis with presence of septated hyphae of Aspergillus fumigatus. These mycelia appeared septated and branched by PAS stain (Fig. 5).

The portal area was highly infiltrated with lymphocytes, macrophages and fibroblast in addition to degenerative changes of hepatic cells (Fig. 6). Multiple focal area of leukocytic reaction including lymphocyte, heterophils and macrophils (Figs. 7 and 8) were observed among necrotic hepatic cells. The hepatic cells were replaced by fibroblast, heterophils and gaint cells around the granuloma (Fig. 9). Focal area of caseous necrosis infiltrated with lymphocytes, macrophages and gaint cells were seen replacing the cardiac muscles. Some myocardial muscle fibers suffered from hyaline degeneration (Fig. 10).

The renal tubules showed focal or diffuse necrosis accompanied with numerous round cells infiltration (Fig. 11). These lesions to some extend was inagreement with Chaudhry et al. (1992); Gab-Allah (1994); Edris et al. (1995) and El-Saida (1998) who reported congestion and leukocytic infiltration in the renal tissue. The presence coagulative necrosis in kidney and hyaline degeneration in cardiac muscles may be due to the ischemia following fungal thrombosis. Fibrosis were seen in the granuloma indicating the chronocity of infections and impairment of macrophage function. These results agreed with Beckman et al. (1994) who mentioned that the macrophage function could by further impaired if chickens were exposed to bad ventilation and ammonia which inhibits phagosome lysosome functions in macrophages and impairs mitogenic responsiveness of lymphocytes. The mycelia of Aspergillus were stained red-septated and branched by PAS. These results were completely inagreement with Ozmen and Dorrestein, (2004) who mentioned that the fungal hyphae were easily demonstrated using Grocott's method and PAS.

Brain showed degenerated neurons, congestion and inflammation of meninges with infiltration of lymphocytes (Fig. 12). These results were to some extent inagreement with those mentioned by Chaudhry et 
al. (1992); Gab-Allah (1994) and Kwon-Yongkuk et al. (1998) who reported necrotic neuron and infiltration of macrophage and giant cells in the brain. Granulomas were noticed in intestinal mucosa and submucosa with infiltration of leukocytes (Fig. 13). Also proventriculus showed aggregation of leukocytes among their glands (Fig. 14). Necrosis and depletion of white pulp of spleen were seen (Fig. 15). These results were some what similar to those mentioned by Gab-Allah (1994) and El-Saida (1998) who reported the mycotic granuloma in the intestine, proventriculus and spleen.

\section{Candidiasis:}

The clinical signs in our examined birds were represented by inappetane, restlessness and some birds regurgitate slimy foul smelling food. These signs were also reported by Farid et al. (1986) and El-Saida (1998) who noticed restlessness and loss of appetite in chickens. The postmortem lesions in our study were detected in oesophagus, crop, proventriculus and gizzard. The lesions were thickening of mucosa which was covered by slimy material adherent to it. The lesions progressed to diphtheritic membrane which was difficult to be removed from the mucosa. Jordan (1990) reported mucosal thickening with opaque colour and in chronic cases a raised white patches or ulceration. Our results were completely agreement with El-Saida (1998) who observed a diphtheritic membrane which was difficult to be removed due to candidiasis.

Histopathologically, hyperplasic changes in the cornified layer of the crop and oesophagus with degenerative and necrotic changes in the superficial mucosa were detected. The necrotic mucosa changed to diptheretic membrane formed from fibrinous network (Fig. 16). The subepithelial tissue showed intense leukocytic infiltration including heterophils and lymphocytes with erythrocytes (Fig. 17).

The above mentioned lesions could be attributed to candi toxin. These findings were supported by Wyatt et al. (1975) who mentioned that Candida albicans produce endotoxin like material. These changes were nearly similar to those obtained by Calnek et al. (1991) who mentioned that candidiasis was characterized by extensive destruction of crop mucosa forming ulcers and diptheretic membrane. Farid et al. (1996) reported similar lesions with the presence of pseudomycelia among the destructed tissues in experimentally infected chickens. Also our results were in complete agreement with El-Saida (1998) who reported degeneration and necrotic changes in mucosa of crop with diphtheritic membrane. 
These investigations throw some lights on the appearance of some mycotic diseases mainly aspergillosis and candidasis in balady chicken farm during winter time (November - April) when there is a great lowering of temperature associated with increased humidity. Aspergillus species including flavus, niger, ochraceaus and fumigaus and also Candida species including C. albicans, C. tropicalis, C. krusei and $C$. parapsillosis were successfully isolated and identified, gross and histopathological lesions were described and confirm the diagnosis.

\section{REFERENCES}

Ajay, P.; Sadana, J.R. and Asrani, R.K. (1991): Studies on clinical and haematological alteration in pneumonic aspergillosis due to Aspergillus flavus in Japanese quail. Mycopathologia, 116 (2): $119-123$.

Akan, M.; Hazroglu, R.; Hazroglu, R.; Ilhan, Z.; Sareyyupoglu, B. and Tunca, $R$. (2002): A case of Aspergillosis in a broiler breeder flock. Avian Disease. 46 (2): 497-501.

Ali, A.A. (1996): Pathological studies on Aspergillus fumigatus in both naturally and experimentally infected chicken. $3^{\text {rd }}$. Vet. Med. Cong., Zagazig 8 - 10 October, 1996.

Bancroft, J.D.; Stevens, A. and Turner, D.R. (1990): Theory and practice of histological technique. $3^{\text {rd }}$ Ed. Churchill Livingstone, Edinburgh, London, Melbourne and New York.

Barnett, J.A.; Payne, R.W. and Yarrow, D. (1983): Yeast characteristics and identification. Cambridge University, Press Cambridge, London, New York, New Rochelle, PP 295- 300.

Barton, T.; Doft, B.M. and Read, D.H. (1992): Tracheal Aspergillus flavus. Avain Disease, 36 (40): 1081- 1084.

Bechman, C.W.; Trampel, P.W.; Debey, M.C.; Richord, T.L. and Niyo, $Y$. (1994): Aspergillus fumigatus keratitis with intraocular invasion in 15 day old chicken. Avian Disease, 38: 660-665.

Bergmann, V.; Heider, G. and Vegel, L. (1980): Mycotic spondylitis as a cause of locomotors disorders in broiler chicken. Monatshre Betefur Veterinary Medizin. 35 (9): 349-351.

Calnek, W.B.; John, H. and Beard, W.C. (1991): Diseases of poultry, $9^{\text {th }}$ ed PP. 138 Lowa State Univ. Press., USA.

Carrasco, L.; Bautista, M.J.; Mulasdelas and Jensen, H.E. (1993): Application of enzymes immunohistochemistry of the 
diagnosis of Aspergillosis, Candidiasis and Zygomycosis in three love birds. Avian Disease, 37: 923.

Chaudhry, S.I.; Hamed, A. and Javed, T. (1992): Clinico pathological studies on aspergillosis in broilers. Pakistan Vet. J., 12: 32 35.

Custen, J. and Fram, J. (1987): Fungal infection in birds in captivity six case reports mykosen. Avian Disease, 30 (4): 166-171.

Dovorak, J. and Acetenasek, M. (1969): Mycological diagnosis of animal dermatophytosis. Academic, 213- 219.

Edris, G.O.; Oraby, F.A. and Azzam, A.A. (1995): Some studies of moulds in Zoo birds of Giza Zoo, Egypt. Vet. Med. Ass. 55 (1, 2): 635-644.

EL-Badry, A.A. and Sokkar, I.M. (1988): Mycotic flora of chicken population in Kena Governorate. Assiut. Vet. Med. J., 19:173.

EL-Batrawi, A.M. (1980): Studies on mycotic infection in poultry with particular reference to Aspergillus fumigatus infection intestine poults farms. M.D. Vet. Medicine, Cairo University.

Ellis, M.B. (1971): Dematioceous hypomycetes Commonwealth Mycological Institute, Kew- Surrey U.K., England pp. 608.

El-Mahdy, M.M.; Hamouda, M.A. and Tahan, F.H. (1994): Histopathological studies on the interaction between aflatoxin and some mycotic infection in chickens. Vet. Med. Journal Giza. 42 (1) B: 215 - 220.

El-Matary, D. (1998): Studies on endotoxin of some Candida species. Thesis of Ph.D. Bact. Immun. and Mycology, Fac. Vet. Med., Zagazig University.

EL-Saida, M.M.E. (1998): Pathological studies of mycotic affections on broiler in large farms. M.V.Sc. Vet. Med. Science Path., Zagazig University.

Faried, A.; Mostafa, T.A.; Torky, H.A.; Hassieb, M.M. and Shaboury, F. (1986): Pathology of experimental candidiasis in chickens. Alex. J. Vet. Sci., 2 page 1.

Gab-Allah, M.S. (1994): Pathological studies on mycotic Aspergillus fumigatus infection. Egypt. J. Comp. Path. Clin. Path., 6 page I (March).

Hofacre, C.L.; Page, P.K. and Fletcher, O.J. (1985): Suspected mycotoxicosis in laying hens. Avian Disease, 29 (3): 846 -849.

Hossain, M.K.; Ahmed, M.; Kabir, H.; Sarker, M.R.R.; Jalil, M.A. and Adhikary, G.N. (2004): Poultry diseases at Rajshahi in 
Bangladesh. Journal of Animal and Veterinary Advances. 3 (10): 657 - 659 .

Iskander, T.; Gholib, D. and Hastiono, S. (1992): Pathological aspect of lung aspergillosis in broiler chickens. Penyakit- Hewan. 24 (43): 48- 51.

Ismael, M.M. (1993): Epidemiology of mycotic affections in poultry with special emphasis on metabolic products. Zagazig Vet. J., 21 (1): $46-47$.

Jordan, F.T.W. (1990): Poultry disease. Jordan, Univ. of Liverpool SF. 9. 95, page 69 .

Kwon-Yongkuk; Mo-Inpil; Kang Minsu; Kim Giseuk; Kang Minsu, Kim Giseuk; Kang- Kyungil (1998): Report of an outbreak of meningoencephalitis in layer chickens caused by Aspergillus species. RDA. J. of Vet. Sci. 40 (1): $54-60$.

Laron, D.H. (1976): Medical importante fungi. A guide to identification. Hagerston Maryland. USA London, UK Harper and Low VII.

Magnolli, C.; Dalcer, A.M.; Chiachiero, S.M.; Miazzo, R. and Saenza, M.A. (1998): Enumeration and identification of Aspergillus. Mycopathologia, 142 (1): 27-32.

Manfre, A.S.; Wheeler, H.O.; Feldman, G.L.; Rigdon, R.H. and Couch, J.R. (1958): Fungi in the crop of the turkey. Am. J. Vet. Res., 19: 659 .

Ononiwu, J.C. and Momoh, M.A. (1983): An outbreak of aspergillosis in poultry. Bulletin of Animal Health and Production in Africa, 31 (1): $75-77$.

Osman, O. (1991): Mycological studies on crop mycosis in chicken. Thesis of Ph.D., Microbial., Fac. Vet. Med., Zagazig University.

Ozmen, O. and Dorrestein, M.G. (2004): Observation of aspergillosis in brains of Turkey poults using different histopathological staining techniques. Biochemic. and Histochemistry. 79 (2): 95 -99 .

Ragheb, R.R.; Saad, A.E. and Tanios, A.I. (1999): Some studies on enteritis in rabbits. Egypt. J. Agric. Res., 77 (4):1847 -1865.

Rahman, M.M.; Das, P.M.; Ban, A.S.M.; Islam M.R. and Rahman, M.M. (2003): Pathological investigation of diseases of broiler in some forms of Mymensingh. Journal of Animal and Vet. Advances. 2 (12): 660 - 665. 
Refai, M.K.; Gobba, A.H. and Reith, H. (1969): Monograph on yeast, diagnosis and treatment. Egypt. Vet. Med. Med. J., 18: 259 316.

Richard, J.L.; Calnek, B.W.; Barnes, H.J.; Beard, C.L. and Reid, W. M. (1994): Aspergillus flavus keratitis with intraocular invasion in 15 days old chicken Lowa State Uni. Press. Ames Lowa. P. 326-334.

Said, S.A. and Sampurnant, C. (1994): Candidiasis in different breeds in chickens. Endicus Vet. J., 67 (1): 79-80.

Samad, M.A. and Chakraborty, S.R. (1993): Outbreak of acute Aspergillosis in broiler birds in Bangladesh. Poultry Adviser of Vet. Med., 26 (5): 63-65.

Singh, J. and Malhotra, F.C. (1979): Segmental gross and histopathological studies on aspergillosis in chicks. Indian J. of Animal Science. 49 (7): 562 -568.

Singh, N.; Grewal, G.S.; Brior, R.S.; Singh, N. and Dhaliwal, B. (1993): Outbreak of mycotoxic tracheitis in domestic fowl. Mycosis, 46 (1-2): 65-67.

Taguchi, M.; Tsukii, M. and Tsuchiyot. (1979): Rapid identification of yeasts by serological methods. A combined serological and biological method. Sabouraudia, 17 (3): 185 -1910.

Utomo, R.N.; Tarmud, Ji and Hastiono, S. (1995): The case of eye aspergillosis in village chicken in Kabuptan Tapin South Kalmiantan. Penyakit- Hewan, 4: 34.

Wyatt, R.D.; Simmons, D.G. and Hamilton, P.B. (1975): Induced systemic candidiasis in young broiler chickens. Avian Disease. 190 (3): 15. 